\title{
Forecasting the outbreak of moorland wildfires in the English Peak District
}

\author{
Kevin Albertson ${ }^{\mathrm{a}}$, Jonathan Aylen ${ }^{\mathrm{b}, *}$, Gina $_{\text {Cavan }}^{\mathrm{c}}$, Julia McMorrow ${ }^{\mathrm{d}}$ \\ ${ }^{a}$ Department of Economics, Manchester Metropolitan University, Mabel Tylecote Building, Manchester M15 6BG, England, United Kingdom \\ ${ }^{\mathrm{b}}$ Manchester Institute of Innovation Research, The University of Manchester, Manchester M13 9PL, England, United Kingdom \\ ${ }^{c}$ CURE - Centre for Urban and Regional Ecology, The University of Manchester, Manchester M13 9PL, England, United Kingdom \\ ${ }^{\mathrm{d}}$ School of Environment and Development, The University of Manchester, Manchester M13 9PL, England, United Kingdom
}

\section{A R T I C L E I N F O}

\section{Article history:}

Received 8 March 2006

Received in revised form

17 January 2009

Accepted 8 February 2009

Available online 25 March 2009

\section{Keywords:}

Climate change

Wildfire

Probit analysis

General to specific

Seasonality

Risk assessment

Forecast

Backcast

Tourism impact

Time series

Plant phenology

National park

\begin{abstract}
A B S T R A C T
Warmer, drier summers brought by climate change increase the potential risk of wildfires on the moorland of the Peak District of northern England. Fires are costly to fight, damage the ecosystem, harm water catchments, cause erosion scars and disrupt transport. Fires release carbon dioxide to the atmosphere. Accurate forecasts of the timing of fires help deployment of fire fighting resources.

A probit model is used to assess the chance of fires at different times of the year, days of the week and under various weather conditions. Current and past rainfall damp fire risk. The likelihood of fire increases with maximum temperature. Dry spells or recent fire activity also signal extra fire hazard. Certain days are fire prone due to visitors and some months of the year are more risky reflecting the changing flammability of moorland vegetation. The model back-predicts earlier fires during a hot dry summer. The impact of climate change on fire incidence is not straightforward. Risks may be reduced if wetter winters and earlier onset of spring add to plant moisture content. Yet a warm spring increases biomass and potential fuel load in summer. Climate change may cause the timing of moorland wildfires to shift from a damper and more verdant spring to drought-stressed summer.
\end{abstract}

(c) 2009 Elsevier Ltd. All rights reserved.

\section{Climate change and moorland wildfires}

\subsection{Moorland fires}

Climate change threatens delicate and cherished landscapes. This study relates to the moorlands of the Peak District National Park in the Pennines of northern England (Fig. 1). Rural uplands are a key visitor attraction in the United Kingdom. Yet they are particularly vulnerable to climate change (Shackley et al., 1998). Warmer, drier summers brought by global warming pose a potential danger of increased frequency of wildfires on moorlands. Similar concerns have been expressed about increased risk of wildfires brought by climate change in the forests of Ontario by Wotton et al. (2003). So the UK Peak District is an exemplar of a global problem. The degraded peatlands of the Peak District lie at the southeastern margin of blanket bog in the UK and have the highest number of visitors of any UK National Park. Under current

\footnotetext{
* Corresponding author. Tel.: +44161275 5931; fax: +44161275 0923.

E-mail address: j.aylen@manchester.ac.uk (J. Aylen).
}

climatic conditions the Peak District can be regarded as an analogue for fire risk on peatlands at higher latitudes during a future drier, warmer climate. Peat accounts for 51 per cent of the carbon content of soils in Britain (Milne and Brown, 1997, tables 13,14).

Moorland wildfires are difficult and costly to fight, damage the ecosystem and cause long-lasting erosion scars (Tallis, 1981; Maltby et al., 1990; Mackay and Tallis, 1996; Anderson et al., 1997). Much peat erosion can be traced to exceptional events, either fires or extreme downpours (Tallis, 1987). Fires can be devastating for small mammals and ground nesting birds (Anderson, 1986, p. 8). ${ }^{1}$ Firedamaged-peat is eroded and deposited in reservoirs where it discolours drinking water supplies and reduces water storage capacity. Heavy metals deposited from airborne industrial pollution in previous centuries are disturbed by burning and leach into water catchments from exposed peat (Yeloff et al., 2005; Rothwell et al.,

\footnotetext{
1 The result of severe fires is a post-Armageddon type landscape with hillocks of burnt peat, exposed peri-glacial rocks and bygone aircraft wrecks. Burn scars provide an ecological niche for one species, the Golden Plover, which prefers open ground for nesting.
} 

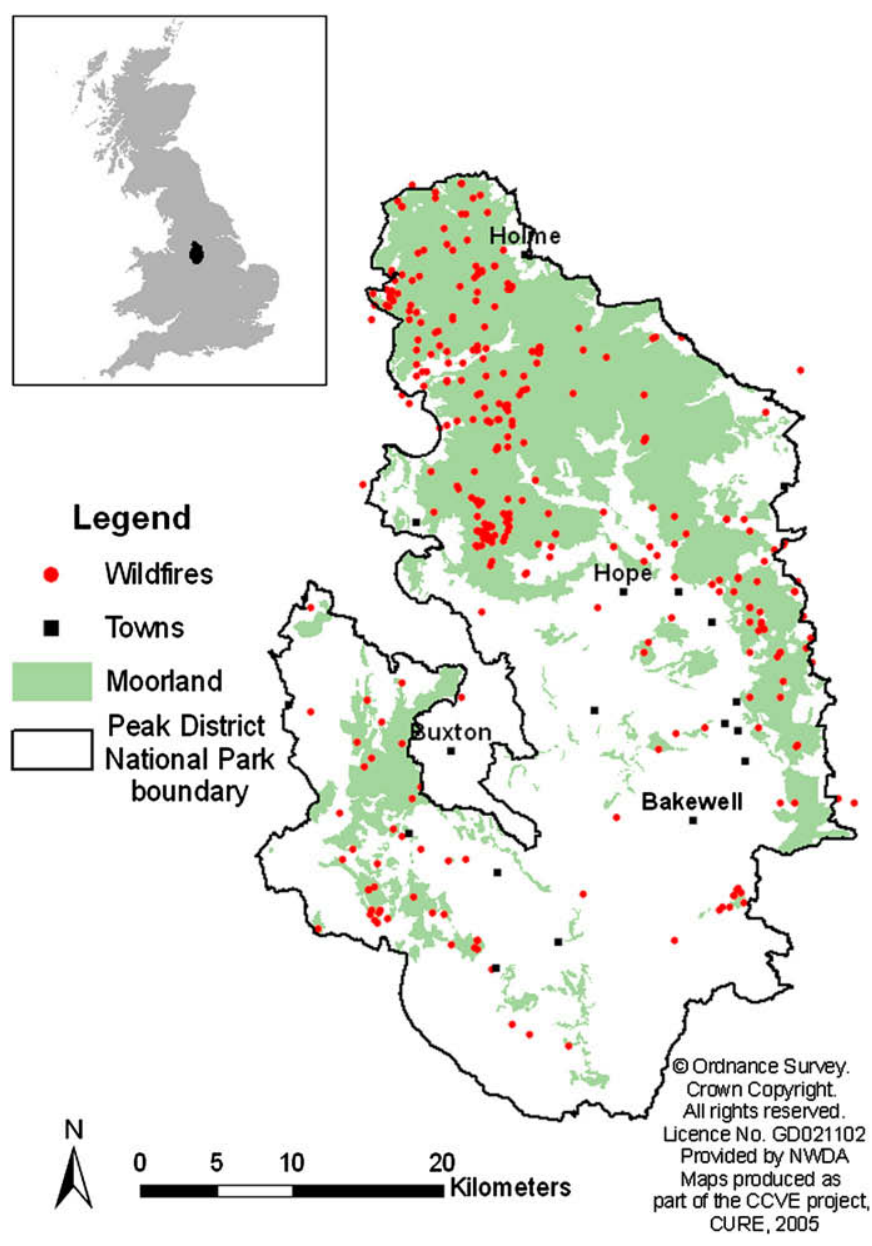

Fig. 1. Peak district wildfires.

2005). Large fires may close major roads and force rerouting of flights to Manchester Airport for short periods at considerable cost. Peat covering much of the north and eastern parts of the park is an important carbon store. Burning directly releases carbon to the atmosphere and contributes to climate change. Other pathways for carbon loss are triggered by erosion of burnt soil, although evidence on methane flux from burnt areas is contradictory (Gray, 2006; Ward et al., 2007).

The moors are a highly managed landscape used for hill farming, grouse shooting, water catchment and recreation. Gamekeepers encourage a mosaic of habitats, including old heather to shelter game-birds and new growth areas. Small patches of heather are intentionally burnt in winter to promote regeneration of new heather shoots in spring on which grouse feed. Managed burning is limited, by law, to the period between 1st October and 15th April (DEFRA, 1992). Most controlled burning activity takes place in February and March when the ground is wet and the superficial vegetation is dry (McMorrow et al., 2009). These burning regimes usually occur on a 10-20 year cycle. Evidence suggests managed burning may have increased over time. This adds to risk of accidental fires in spring if burns get out of control, yet reduces fuel load and fire risk in summer, thereby altering the seasonality of fire outbreaks over time (Yallop et al., 2006).

Our concern is wildfires. They cause severe and extensive damage if they set into the underlying peat soil, where they can continue burning for weeks and cause loss of soil organic matter and nutrients (Shaw et al., 1996). Wildfires are defined here as those started accidentally or maliciously, or managed fires that get out of control. For the most part, human negligence or malice is to blame for moorland wildfires. Fires due to lightning strikes are rare. Wildfires are caused by various factors including cigarettes discarded by visitors, poorly extinguished camp fires and barbecues, the lens effect of glass litter, arson and intentional fires directed at heather burning which run out of control. The moors may have to be closed to public access at times of high fire risk.

Over a 27 year period ending on 1st August 2004 there were 353 moorland wildfires in the Peak District National Park Fire Rangers' Log (Appendix 1). These logs record fires of all sizes and causes, though some fires in remote locations may burn out unreported. Nearly one third of all fires took place during just four individual months within our sample: the very hot, dry summer of July and August 1976, and the dry spring of March and April 2003 (Fig. 2). Records are sketchy before 1976. In 1959, before our sample begins, the Derbyshire fire brigade alone received 700 reports of moorland fires between September 1st and 11th - an under-estimate of fires at the time since the Peak District is also covered by neighbouring fire authorities (Radley, 1965). A small change in the weather can alter the chance of a wildfire occurring from a rare event to a commonplace and severe nuisance.

Few attempts have been made to assess systematically the effect of weather, soil and plant conditions and visitor numbers upon the prevalence of wildfires in the UK. A study of Peak District fires by Anderson (1986) concludes rainfall deficit during recent months relative to what might have been expected for the time of year is a good predictor of wildfires. More generally, Palutikof (1997) finds a positive relationship between the number of "secondary fires" (including category 2: grassland fires) and temperature, and a negative relationship between such fires and rainfall, across England and Wales over the period 1984-1995. Secondary fire increases due to the hot, dry summer of 1995 occurred mainly in grass and heathland, the landscape of concern here.
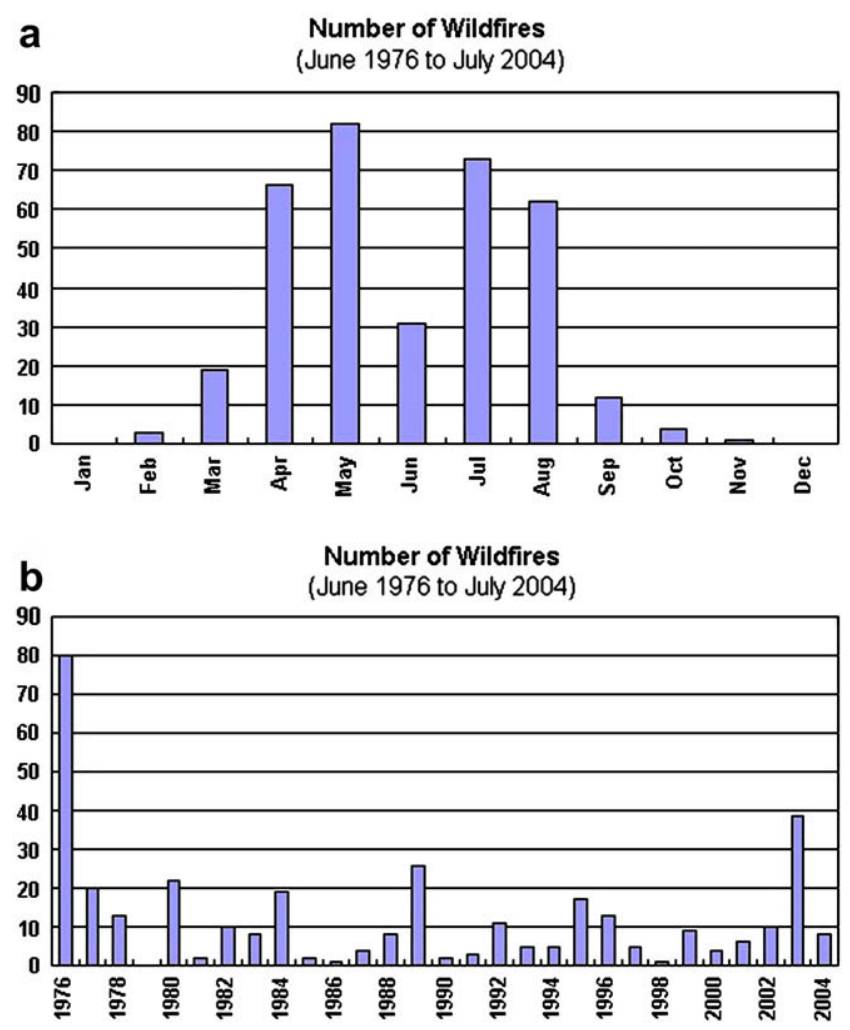

Fig. 2. The occurrence of wildfires. 
The impact of weather and human activity on fire risk has to be established in order to forecast the effect of changing visitor numbers and climate. Development of statistical models allows us to assess the efficiency of existing prediction models based on meteorological considerations. Accurate forecasts of the likely timing and location of fires help deployment of fire fighting resources.

\subsection{The impact of climate change}

Climate change models for Northwest England suggest the climate will get milder (Hulme et al., 2002). The UK Meteorological Office Hadley Centre climate models suggest a warming of the average summer maximum temperature by up to $5^{\circ} \mathrm{C}$ by the $2080 \mathrm{~s}$ (2071-2100), depending on the level of future emissions. This means average summer maximum temperature is likely to increase from $18{ }^{\circ} \mathrm{C}\left(1961-1990\right.$ average) to about $23^{\circ} \mathrm{C}$ in the Northwest of England (McEvoy et al., 2006). Additionally, changes in rainfall are expected to be considerable, with up to $45 \%$ decrease in summer rain and $23 \%$ increase in winter precipitation by the 2080 s.

The potential effect of climate change on wildfire risk is not straightforward. Plants adapt to environmental conditions. The vulnerability of the Peak District to wildfires alters from day to day with plant phenology. Water held in plants strongly influences fire behaviour (Davies, 2005, ch.2). Increased winter precipitation means plants and soil will be wetter in spring. When spring arrives, new green shoots supplant fire prone dead plant tissue from the previous year. Higher maximum temperatures raise the risk of fire, but at the same time, higher minimum temperatures advance plant growth. The advance of spring should not be exaggerated as plant growth also depends upon duration of daylight (Sparks et al., 2000). Precise dates for the onset of spring vary with altitude. As plants progress through into summer the amount of fuel accumulated in biomass is correspondingly higher at a time when seasonal availability of water is reduced. Warmer, drier summers mean soil moisture will fall and evapotranspiration from vegetation will rise. So, climate change may cause the timing of moorland wildfires to shift from a damper and more verdant spring to drought-stressed summer.

Climate change is likely to extend the length of the fire season. The high risk period for fires on the moors will spread into autumn as soil moisture takes longer to recover after warmer, drier summers. Models of the incidence of forest fires show that a doubling of carbon dioxide levels in the atmosphere significantly lengthens the fire season (Wotton and Flannigan, 1993).

Warmer, drier summers and milder winters may encourage tourism and outdoor recreation, though the evidence is equivocal. Aylen et al. (2006) find visits to a country leisure site are unaffected by temperature. Rainfall merely switches visitors from wet days to dry days. Other research suggests the UK tourism industry benefits from warm summers (Giles and Perry, 1998). In the same vein, Agnew (1997) estimates 5\% more domestic holidays and 30\% more short breaks were taken in the hot summer of 1995.

\subsection{The structure of the paper}

This paper reports development of a probability model to assess the chance of fires at different times of the year, different days of the week and under various weather conditions, allowing for seasonality in the data.

In Section 2, the sample of wildfires and its seasonal character is discussed. Section 3 analyses the time series properties of the data. Section 4 outlines a probit model for the likelihood of moorland wildfires and Section 5 discusses the general to specific methodology used and estimation of results. This model is tested out-ofsample against a data set for the severe fire year 1976/7 in Section 6.
We consider extensions of the model in Section 7 and draw conclusions about the implications of climate change for wildfires in Section 8.

\section{The seasonal nature of wildfires}

Our sample of daily fires is drawn from record books on fire incidents kept by rangers in the Peak District National Park. Data is available for the period 1st June 1976 to 1st August 2004, though we retain the data for 1976/7 for out-of-sample forecasting. Record books may understate fires if incidents are dealt with locally and pass unreported. There is spatial bias in reporting. Fires are more likely to occur close to roads and footpaths and these are also more likely to be recorded.

The seasonal nature of fires is complex. The occurrence of fires varies with the time of year and even within each week. The peak months for fires are April and May (Fig. 2). The chance of a fire in April or May is approaching one in ten. But this conceals fluctuations from year to year. Nearly one third of all the 353 moorland wildfires in the Peak District in our database took place during just four individual months: the very hot, dry summer of July and August 1976 - which is outside the sample used for estimation and during the dry spring of March and April 2003.

More fires are reported at weekends and bank holidays, reflecting the impact of recreation activity. ${ }^{2}$ (There may be a distinction between the ignition of a fire and the date it is reported. It is said weekend fires are often reported on a Monday. We find no statistical confirmation of this particular fire lore.) There is no direct evidence on variations in visit levels since the Peak District National Park is open to public access and crossed by major roads. So we proxy visit levels by days of the week, with extra dummy variables for bank holidays and school holidays. Fire occurrence is not confined to warm days. A single fire in January ignited at a temperature of $-0.5^{\circ} \mathrm{C}$. Fires can burn across dry winter vegetation above frozen soil, although these are likely to be controlled surface burns used by land managers to renew heather.

\section{Analysis of time series properties}

Our weather data are daily precipitation and temperature from Buxton, a town close to the centre of the Peak District National Park. Assessing climate trends is highly controversial as Kallache et al. (2005) show in the context of flood behaviour. A surprising feature of Buxton weather data is its long run stability. Climate change may be defined, in time series terms, as a persistent change in the first two moments (mean and standard deviation) of meteorological data (i.e. covariance non-stationarity). Non-stationarity implies long run climate behaviour dominates the impact of short-run weather effects (Woodward and Gray, 1995). Yet we find the impact of climate is no more than the sum of short-run responses to daily and seasonal weather variation. There is no evidence of climate change in our data apart from a shift in the seasonal distribution of rainfall. We concur with Kallache op.cit. that climate change may only be observable with a time delay and with complex patterns. Daily weather data is a poor basis for discerning underlying climate trends.

Taking monthly data, the weather in the Peak District appears stationary over the 27 year period. That is to say neither the average nor the variance in the level of temperature and precipitation alters significantly over time. Winter weather at Buxton appears to have got slightly warmer over time - at least since 1987 - but this is not

\footnotetext{
${ }^{2}$ Bank holidays are statutory holidays in the UK, usually occurring on a Monday in Spring and Autumn.
} 
statistically significant. Autocorrelation functions show no evidence of a unit root at regular intervals in the residuals of a seasonally adjusted auxiliary regression equation, for rainfall, maximum or minimum temperature, or temperature range (Fig. 3). There are no significant seasonal unit roots. These findings are consistent with Thompson (1999) who finds no particular trend to precipitation in Britain over the last 150 years, although there have been substantial variations from year to year.

Osborn et al. (2000) and Osborn and Hulme (2002) suggested daily precipitation has become more intense in winter and less intense in summer over the period 1961-2000. This enhanced seasonal cycle of increasing winter precipitation, heavier downpours and drier summers with fewer wet days and lighter rainfall may reflect changes in the mid-latitude westerly circulation (Mayes, 1996). Mayes shows there has been more rainfall in Northwest England in early spring, which would damp the moors ahead of the high risk fire season in April and May. Subsequent results from Maraun et al. (2008) confirm growing rainfall intensity in winter and spring for the UK, but suggest changes in summer rainfall intensity show no long run trend. These results are crucial for modelling incidence of moorland fires as more intermittent and less intense summer rainfall may increase the risk of fire.

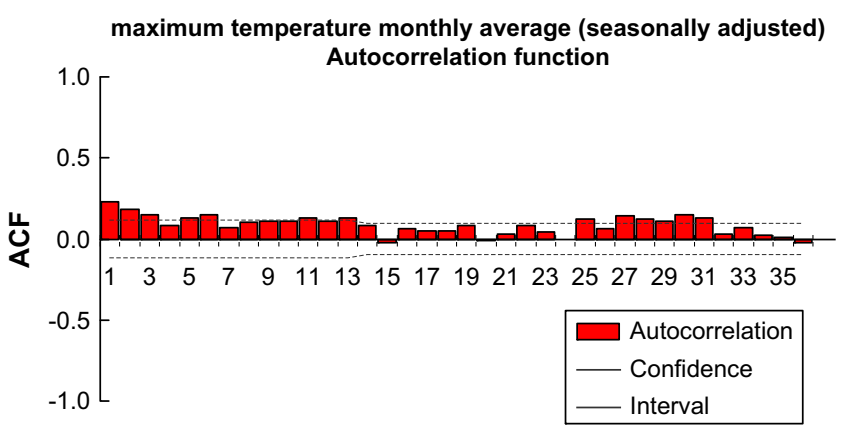

lags

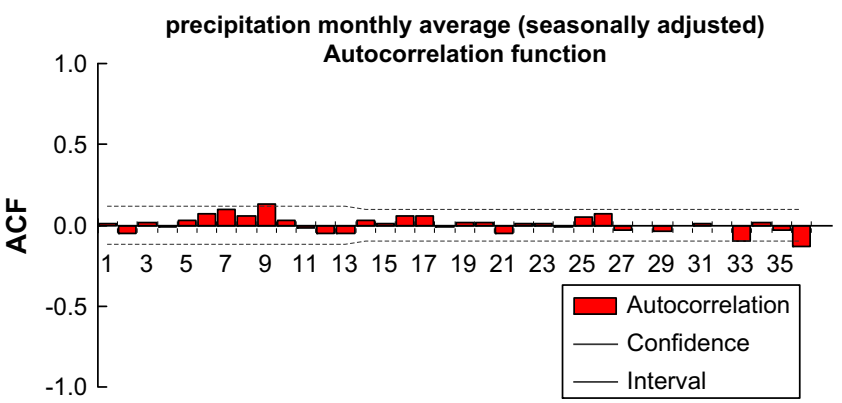

lags

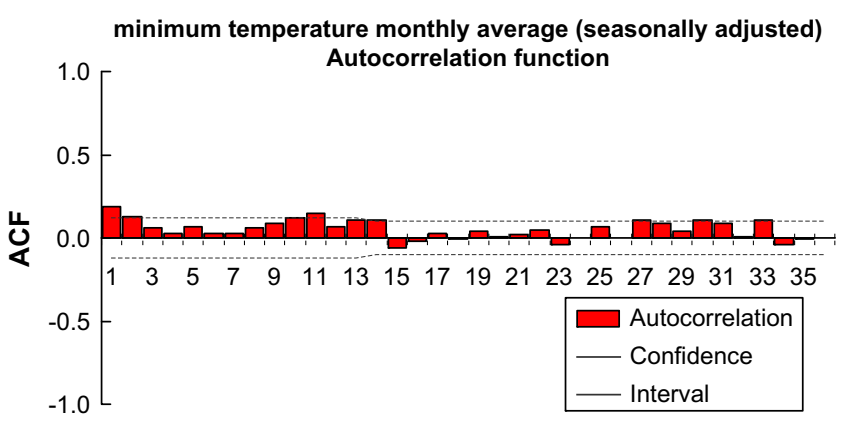

lags

Fig. 3. Autocorrelation functions of monthly averages of weather variables: residuals from auxiliary regressions on monthly seasonal dummy variables.

\section{Modelling the probability of fires}

One approach to modelling ecological disturbances such as wildfire events relies on a Poisson process for extreme values (e.g. Dayananda, 1977; Mandallaz and Ye, 1997; Wotton et al., 2003). Extreme event studies consider observable distributions (e.g. Gaines and Denny, 1993). For example, Davison and Smith (1990) and Katz et al. (2005) appeal to a Pareto distribution of extreme outcomes to model infrequent but unusual events. Poisson models are an ideal way to model the number of fires.

Instead, the approach here is to consider the chance of a wildfire breaking out on a given day. In these circumstances a stochastic binary model, such as probit, is applicable. Other probability based models of wildland fire adopt a similar technique, logit analysis, for computational reasons (Martell et al., 1987; Vega Garcia et al., 1995; Preisler et al., 2004). In practice, modelling using Poisson regression gives very similar results to probit, but slightly less accurate out-ofsample forecasts (results are available from the authors.)

\subsection{Probit}

Probit analysis offers a convenient functional form for estimating a probability model with an observed dependent variable, $y$, of either zero ("no fire") or one ("fire or fires occur") where $y_{i}$ is the outcome of a binomial process on the $i$ th day. (See, for example, Johnston and DiNardo, 1997). We can define an implicit latent variable $y^{*}$, such that:

$y_{i}=\left\{\begin{array}{ll}1 ; & \text { if } y_{i}^{*}=X_{i} \beta+\varepsilon_{i}>0 \\ 0 ; & \text { else }\end{array}\right.$,

where $X$ is a vector of observable explanatory variables (Appendix $2) ; \varepsilon_{i}$ is an unobservable aleatoric element, which we assume is independently normally distributed with a mean of zero and a standard deviation of $\sigma ; y^{*}$ is normally distributed, conditional on $X$, and $\beta$ can be estimated using maximum likelihood estimation. Therefore,

$\operatorname{Pr}\left(y_{i}=1\right)=\Phi\left(\frac{X_{i} \beta}{\sigma}\right)=\int_{-\infty}^{\left(\frac{X_{i} \beta}{\sigma}\right)} \frac{1}{\sqrt{2 \pi}} e^{\left(\frac{-z^{2}}{2}\right)} \mathrm{d} z$,

\subsection{Capturing seasonality}

Seasonality can take a number of forms in time series models (e.g. Franses, 1996). Stochastic seasonality, (or seasonal unit roots, Hylleberg et al., 1990), is ruled out by the fact that we find the data are stationary. We assume seasonal fluctuations in daily fires can be represented deterministically using seasonal dummy variables. These dummy variables include the month of the year, the day of the week, the presence of a bank holiday and school holidays. These dummy variables are intended to capture a shift in the mean probability of a fire for those days over and above other factors at work. Deterministic seasonality is a special case of a broader group of seasonal models (Albertson and Aylen, 1996). Alternative specifications are not readily handled with daily data. Nor is there reason to suppose seasonal effects, such as weekend peaks in visitors, vary from year to year. However, we do find periodic seasonality in the relationship between maximum and minimum temperature over the course of a year.

\subsection{Variable specification}

Temperature is specified in terms of both maximum daily air temperature and minimum temperature, which usually occurs at night, in degrees Celsius. Precipitation is accumulated rainfall or 
snowfall in the past $24 \mathrm{~h}$ measured in millimetres of moisture at 0900 GMT.

High temperatures and low precipitation have a cumulative effect on fire risk. Moisture evaporates and is transpired from plants. A moisture deficit builds up. The water table drops in peat bogs leaving a baked and cracked surface held together by plant mass. Dry vegetation and peat is more likely to ignite. So we are concerned to capture two related concepts: the cumulative effect of weather on local conditions and the idea of a "dry spell", or "hot spell". In turn, these biophysical hazards interact with human risk because there are likely to be more people on the moors in hot dry weather, giving rise to more likelihood of ignition and more chance of a fire being reported.

The cumulative effect of precipitation and temperature is expressed through rainfall and temperature temporal shadows the lagged effect of recent weather. To calculate rainfall shadow, for example for the past week, we proceed as follows: Firstly, we take seven day moving averages across the whole sample period and calculate the typical moving average for each date in the year. (On leap years, 29th February is assumed to be the average of 28th February and 1st March). This captures the idea of "typical weather" for the time of year. Secondly, daily rainfall shadow is the actual moving average precipitation ending on that day, minus the typical moving average for those dates across all years in the sample. This gives an indicator of departures from usual weather over the past week. Fourteen, twenty-one and fifty-six day rainfall and temperature shadows are calculated in a corresponding way. Longer rainfall shadows encompass shorter shadows in order to capture the cumulative effect of dry weather. This creates potential multicollinearity which implies caution when interpreting coefficients, but is less of a problem when using the model for its intended purpose of forecasting. Rainfall and temperature shadows are eliminated hierarchically by testing restrictions on the longest shadows first.

The distribution of daily rainfall both for the Peak District and the British Isles resembles a gamma distribution (Coe and Stern, 1982; Stern and Coe, 1984; Chandler and Wheater, 1998; Spanos, 1999, ch.3). On a typical day, precipitation is less than $1 \mathrm{~mm}$. Median rainfall at Buxton is only $0.7 \mathrm{~mm}$. Average rainfall is much higher at $3.6 \mathrm{~mm}$ as the mean is pulled upward by extreme events, such as torrential downpours, that occur from time to time.

Bearing this in mind, dry spells are defined in terms of the deciles of the rainfall distribution. If the rainfall in the past seven days is in the bottom decile for that time of year, we set an indicator variable for a dry period at 1 . Once classified as unity, the indicator dummy remains such until there is a seven day period of above average rainfall for that time period. ${ }^{3}$ The same approach is adopted to categorise an "hot spell". (Temperature is easier to handle statistically.) Surprisingly, 26\% of days fall into "dry spell" clusters as defined here. The frequency of dry spells reflects the episodic nature of rainfall. Indeed, the problem of moorland wildfires would barely exist if rainfall was evenly distributed over time.

There is an added complication that precipitation levels do not capture the duration of daily rainfall. The surface of dry peat becomes "hydrophobic". Intense storms may run off quickly and barely reduce fire vulnerability (McMorrow et al., 2006). Prolonged gradual rainfall is required to soak vegetation and soil.

The dummy variables "fireweek" and "multifire" reflect the occurrence of fires in the previous seven days. These can be interpreted as the difficulty of fully dousing a fire that has set into peat

\footnotetext{
${ }^{3}$ Alternative specifications for these hot spell and dry spell clusters were tested and gave almost identical results, suggesting the model is robust with respect to these variables.
}

subsoil; the persistence of circumstances favouring a fire over time; or a symptom of spatial autocorrelation in our data as new fires flare up near previous incidents (for instance due to wind-blown cinders). Spatial autocorrelation may manifest itself as time series autocorrelation if adjacent fires are sparked on successive days. Those with local knowledge of fire behaviour advise that fires in peat reappear again in the same location after smouldering for long periods, although the process of slow, sustained combustion in the presence of limited oxygen is not fully understood. So in statistical terms, concealed combustion is likely to appear as time series autocorrelation.

The moors are occasionally closed to public access due to high fire risk. The moors were also shut due to the outbreak of foot and mouth disease from late February to late May 2001 - potentially a time of high fire risk. These closure days are accounted for by a dummy variable, although data on closure dates is incomplete. There is no guarantee these emergency restrictions are observed by the public. In any event, most fires start close to public rights of way that cannot be closed. Roads through the park also remain open which means the moors are still vulnerable to cigarettes discarded from cars.

Monthly dummies may capture both changes in plant phenology with the time of year and seasonal shifts in visitor behaviour. Dummy variables for days of the week, bank holidays and school holidays relate to visitor activity.

\section{Methodology and estimation}

\subsection{The general to specific approach}

All estimates were arrived at using a "general to specific" approach to model evaluation associated with David Hendry (Davidson et al., 1978; Gilbert, 1986). This involves estimation of a very general model for the occurrence of fires encompassing a wide range of weather and visitor related explanatory variables, and testing successive restrictions on these variables. Relative importance of effect is determined by absolute values of $t$-ratios. General to specific modelling which successively eliminates explanatory variables is the opposite approach to stepwise regression which successively adds variables, used for instance by Martell et al. (1987).

The resulting model should be consistent with knowledge about physical processes and human behaviour and also account for the underlying statistical properties of the data set. The final model in Tables 1 and 2 began with 33 variables. Successive tests of restrictions reduced this to a final set of 15 explanatory factors. Taking, for instance, days of the week; only Friday, Saturday and Sunday turn out to be significantly different in terms of explaining fire incidence from Wednesday, the initial base case.

Models are estimated using daily data beginning 1st February 1978 to 1st August 2004. The second half of 1976 and the first half of 1977 is set aside for model validation. Multi-fire days are counted simply as fire days (i.e. $y_{i}=1$ ). November, December and January are eliminated from the estimation period as there is only one fire recorded during these winter months across the whole sample period. For some of the time the moors would have been snow covered and not susceptible to fire. In the forecast function, the probability of wildfires in these months is assumed to be negligible.

The use of "seasonal" dummy variables implies selection of an initial base, with which other "seasons" (holidays, days and/or months in our case) may be compared. We select as our base a Wednesday in October (neither a bank holiday nor a school holiday) for which there was no fire in the previous week and not in a dry spell. 
Table 1

Final Probit model of the likelihood of moorland wildfire day. Estimated in levels. Sample period 1st February 1978 to 1st August 2004. Daily observations from February to October.

\begin{tabular}{lclrl}
\hline Variable & Coefficient $\beta$ & Standard error & \multicolumn{1}{l}{$z$} & $\operatorname{Pr}>|z|$ \\
\hline Fire past week & 0.463 & 0.107 & 4.31 & 0.000 \\
Precipitation & -0.080 & 0.023 & -3.47 & 0.001 \\
Minimum temp & -0.082 & 0.016 & -5.21 & 0.000 \\
Maximum temp & 0.108 & 0.013 & 8.51 & 0.000 \\
Bank holiday & 0.606 & 0.158 & 3.85 & 0.000 \\
Friday & -0.300 & 0.142 & -2.11 & 0.035 \\
Saturday & 0.250 & 0.104 & 2.42 & 0.016 \\
Sunday & 0.280 & 0.101 & 2.76 & 0.006 \\
April & 0.592 & 0.116 & 5.10 & 0.000 \\
May & 0.442 & 0.103 & 4.30 & 0.000 \\
R21 & -0.101 & 0.037 & -2.74 & 0.006 \\
R56 & -0.111 & 0.046 & -2.43 & 0.015 \\
IR7 & 0.237 & 0.092 & 2.57 & 0.010 \\
T28 & 0.094 & 0.027 & 3.46 & 0.001 \\
Constant & -3.51 & 0.164 & -21.5 & 0.000 \\
\hline
\end{tabular}

Estimated using maximum likelihood; No. of Observation $=7287$; Log likelihood $=-614.1$; Likelihood Ratio $\chi^{2}(14)=525.4$; Prob $>\chi^{2}=0.0000$; Pseudo $R^{2}=0.2996$.

$z$ is the test statistic for the null-hypothesis "the true coefficient value is not significantly different from zero", normally distributed if the null is true and $\operatorname{Pr}>|z|$ is the probability of wrongly rejecting the null-hypothesis. A coefficient is significantly different from zero if $\operatorname{Pr}<0.05$. The Likelihood Ratio gives a test of the null "none of the coefficients differ significantly from zero" and Prob $>\chi^{2}$ represents the probability of wrongly rejecting that null-hypothesis.

\subsection{Results - the probability of a "fire day"}

Results of the probit model are given in Tables 1 and 2. The dependent variable being explained is "the probability of a fire or fires occurring that day". We report both the coefficients of the estimated model which determine the probit "score" (Table 1) and the change in probability associated with a small change in the explanatory variable from its mean (Table 2 ). In the case of dummy variables, coefficients represent the change in probability of a fire resulting from a switch in value from zero to one, keeping other variables at their mean and other dummies at zero. For example, Table 2 suggests a typical Friday is 0.3 per cent less likely to have a fire (meaning, of course, it is not a bank holiday, does not fall in April or May, did not witness a fire in the past week and is not in an unusually dry period.)

Table 2

Probit model of the likelihood of moorland wildfire $(P)$ calculated at mean values and dummy variables set at zero.

\begin{tabular}{|c|c|c|c|}
\hline Variable $(x)$ & $\partial P / \partial x$ & Mean value $(\bar{x})$ & $\begin{array}{l}\text { Proportion of days } \\
\text { in sample where } \\
\text { dummy takes value } 1\end{array}$ \\
\hline Fire past week & $0.010^{\mathrm{a}}$ & dummy variable & $4.8 \%$ \\
\hline Precipitation & -0.001 & $3.3 \mathrm{~mm}$ & \\
\hline Minimum temp & -0.001 & $6.1^{\circ} \mathrm{C}$ & \\
\hline Maximum temp & 0.001 & $13.0^{\circ} \mathrm{C}$ & \\
\hline Bank holiday & $0.017^{\mathrm{a}}$ & dummy variable & $2.6 \%$ \\
\hline Friday & $-0.003^{\mathrm{a}}$ & dummy variable & $14.3 \%$ \\
\hline Saturday & $0.004^{\mathrm{a}}$ & dummy variable & $14.3 \%$ \\
\hline Sunday & $0.005^{\mathrm{a}}$ & dummy variable & $14.3 \%$ \\
\hline April & $0.014^{\mathrm{a}}$ & dummy variable & $11.1 \%$ \\
\hline May & $0.009^{\mathrm{a}}$ & dummy variable & $11.5 \%$ \\
\hline R21 & -0.001 & -0.002 & \\
\hline R56 & -0.001 & -0.007 & \\
\hline IR7 & $0.004^{\mathrm{a}}$ & dummy variable & $26.3 \%$ \\
\hline $\mathrm{T} 28$ & 0.001 & -0.006 & \\
\hline
\end{tabular}

$P \equiv \operatorname{Pr}\left(y_{i}=1\right)$ see equation (2).

Observed probability of fire on a typical day in our estimation period $P=0.0259$; Predicted $P=0.0042$ at mean.

a Discrete change of dummy variable from 0 to 1 .
It is apparent some factors contribute more fire risk than others, especially the influx of visitors to the area as proxied by the day of the week and occurrence of bank holidays. It is human impact, rather than meteorological pressure that emerges as the main villain of the peace. Daily precipitation, past rainfall (R21, R56) and temperature (T28) shadows and the "dry spell" indicator function (IR7) are significant - all of which point to the role of moisture in damping down fire risk. But these variables have relatively slight effect. A typical British bank holiday is almost five times more perilous than seven days of dry weather.

Higher maximum temperatures are clearly associated with greater fire risk, reflecting the dangers of hot, sunny days in sparking fires. Conversely higher minimum temperatures are associated with a lower fire risk. Minimum temperature at night is a proxy for the onset of spring (Watt, 1954). Warmer days and the absence of night frost trigger plant growth: greener vegetation is less prone to fire than old, dry, shrivelled plants that survive winter by withdrawing moisture from their stems. Growth of vegetation in spring is one reason April is 1.6 times riskier than May, holding everything else equal.

Bank holidays are risky, with the added chance of 1.7 in a 100 of a fire at the mean, over and above the underlying level of risk for that day. School holidays are included as a potential explanatory variable because arson by children is reputed to be a cause of wildfires (McMorrow et al., 2006). There is no statistical evidence to support this view. Either the observation is apocryphal, junior arsonists are persistent truants, or the activities of juveniles are restricted to localities outside the Peak District. Moor closure made no significant difference to the prevalence of fires, perhaps due to shortcomings in the data: Some closure dates are unrecorded; there is no evidence on compliance, with one fire occurring while the moors were officially closed. We cannot draw conclusions about the effectiveness of closure as a policy to reduce fire risk.

Inclusion of a dummy taking the value unity if there was one or more fire in the previous week suggests either circumstances conducive to a fire, or possibly time series or spatial autocorrelation between local fire incidents. A similar result is reported by Mandallaz and Ye (1997). "Hot spells" are not significant, although dry spells remain in the final model. Inspection of the data suggests hot spells are characterised by occasional thunderstorms and torrential rain.

\section{Forecasting outbreaks of fires}

\subsection{The risk of fire}

The potential impact of global warming is illustrated by considering Spring Bank Holiday in May (Fig. 4). ${ }^{4}$ This is a high risk day used to illustrate the workings of the model. In 1978 there were seven fires on Spring Bank Holiday - the hottest such day in our sample, with a temperature of $22.5^{\circ} \mathrm{C}$. Our data shows, under current climate conditions, the risk of a fire (or fires) on this particular day is observed to be about $8 \%$. We evaluate the probit function for the average climate on such a day, with maximum temperature rising from $8{ }^{\circ} \mathrm{C}$ to $25^{\circ} \mathrm{C}$ and thus consider the likelihood of a fire (or fires) being reported. We allow for the corresponding rise in minimum temperature, which has both a deterministic and a periodic relationship with maximum temperature across the year.

\footnotetext{
4 The cumulative normal density function is difficult to evaluate (see Burington, 1973, table 18, pp.424-7). Excel subroutine NORMSDIST calculates the area under a cumulative normal standardised distribution, converting a probit $z$ score into a probability that a dependent variable is less than a given value.
} 


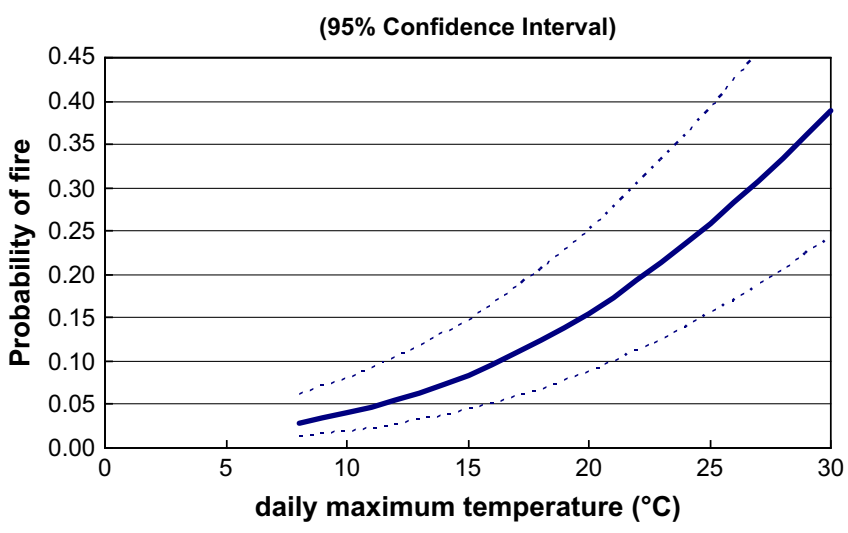

Fig. 4. Probability of a fire on a Spring Bank Holiday: variation with temperature.

The average maximum temperature for Spring Bank Holidays in our sample is $14.87^{\circ} \mathrm{C}$. The ex-post risk of a fire that particular day is $2 / 26=7.7 \%$. Our model predicts an $8 \%$ chance of a fire at the average temperatures prevailing on a typical Spring Bank Holiday. The probability of a fire rises non-linearly from $3 \%$ at $8{ }^{\circ} \mathrm{C}$, to $26 \%$ at $25{ }^{\circ} \mathrm{C}$, with a confidence range from $15 \%$ to $39 \%$ (Fig. 4)

The overall fit of our model can be re-expressed using a contingency table. We apply our probit model to 26 years of data, including the winter months in which we predict no fires (there is only one winter fire recorded in 27 years) (Table 3 ). As the probit model forecasts probability of a fire, we choose a threshold level for declaring a particular day a fire risk. A higher threshold means fewer false alarms, but more fires un-forecast. Here we define a chance of fire that day of $5 \%$ or greater as representing a serious risk.

Naturally, it is easy to predict "no fire days" as they are prevalent. The usefulness of the model comes in predicting "fire days". A prediction of an outbreak of fire is correct one in seven times (i.e. 14\%). This is a function of the cautious threshold chosen for alerts. Expressed in annual terms, we correctly predict five out of seven wildfires in a typical year. In practical terms, there is a trade-off between unanticipated wildfires and the cost of deploying fire watchers and keeping fire crews on standby. If fire crews were alerted to standby on the basis of these forecasts, typically for 36 days a year, they would anticipate nearly three quarters of the fires.

\subsection{Out-of-sample fit}

A key test of the specification of our probit model is its ability to predict a virgin data set. Here we use backcasting - checking the validity of our model using data prior to our estimation period. Backcasting, or backdiction as it is sometimes known, gives the same results in trials as forecasting against hold out data (Scott Armstrong, 2001). In this case it is particularly appropriate given

Table 3

Contingency table for moorland wildfires (25th November 1977 through 1st August 2004).

\begin{tabular}{lrrlll}
\hline \multicolumn{2}{l}{ Probit Forecast "Fit" } \\
\hline & PF & PNF & PF & PNF & \\
F & $14 \%$ & $1 \%$ & $71 \%$ & $29 \%$ & $100 \%$ \\
NF & $86 \%$ & $99 \%$ & $9 \%$ & $91 \%$ & $100 \%$ \\
& $100 \%$ & $100 \%$ & & & \\
\hline
\end{tabular}

Based on $n=9747$ days, 190 of which are "fire days".

PF refers to a day on which a fire is predicted, where the probit function indicates there is a "significant" ( $5 \%$ threshold) probability of a fire.

F refers to a day on which there is a fire: Similarly PNF and NF refer to days on which no fire is predicted, and when there is no fire respectively. Thus, for example, the $e x-$ post proportion of in-correct predictions of "No Fire", is $1 \%$. the extreme weather during the summer before our estimation interval.

We use the model estimated between 1978 and 2004, as outlined in Table 1, to predict fire days for the second half of 1976 and the first half of 1977 (temperature data is missing for Buxton from 1st June to 29th August 1977). This is a tough but appropriate test as the hot summer of 1976 was a bad time for fires. The model must forecast satisfactorily out-of-sample in these circumstances if it is to be applied to analyse the impact of a hotter climate in future. The year 1976 is an appropriate analogy for climate change as many of the fires occurred late in the summer. Recall, climate change indicates shifts towards wetter winters, earlier springs, and hotter and drier summers.

A backcast on the hold out sample using our probit model shows we predict the precise timing of fire days $63 \%$ of the time (Table 4 ). We over-predict the total number of fire days at the $5 \%$ threshold, anticipating 55 fire days when there were only 40 actual fire days. This is to be expected as visitors to the moors are specifically encouraged to be more careful in their behaviour at times of extreme fire risk such as 1976. It is said, but we cannot substantiate, that an emergency order was issued to close the moors on safety grounds that year. Visual inspection of the predictions shows the probit model is very good at anticipating high risk periods but the precise timing of the forecast fire day is often out by just a day or two (Fig. 5). High fire probability days are usually associated with multiple fires.

In order to assess goodness-of-fit of our forecasts, we also compare the backcast predictions with a naïve seasonal model of the ex-ante probability of a fire in any given month (Table 4). Consider the ex-post probability of a fire in month $m, p_{m}$. A fire is "forecast" by the naïve model on day $t$ if $U_{t}<p_{m}$ where $U_{t} \sim U[0,1]$. Thus, fires are "forecast" at random, in such a way that the proportion of "forecast" fires in a month is determined by the expost proportion of actual fire days.

Considering days when fires occurred in our hold out sample, only $5 \%$ were forecast by the naïve model compared to $63 \%$ forecast by the probit model. Conversely, if the probit model predicts "no fire" it is $95 \%$ accurate, while a naïve prediction of no fire is only $89 \%$ accurate.

\section{Further research}

The probit model has wider application in forecasting similar spatially distributed hazards such as forest fires, where there is a need to manage prescribed burning and alert recreation visitors and local residents to dangers posed by wildfires (Morehouse, 2001.) A local forecasting systems based on expert judgement of the sort outlined by Abramson et al. (1996) could predict extreme weather conditions likely to induce fires.

There is more than one fire on some days. The largest number of daily fires reported during the estimation period is seven. Ordered

Table 4

Backcasts of wildfires (1st June 1976 through 31st May 1977).

\begin{tabular}{|c|c|c|c|c|c|}
\hline \multicolumn{6}{|c|}{ Probit Model } \\
\hline & PF & PNF & PF & PNF & \\
\hline $\mathrm{F}$ & $45 \%$ & $5 \%$ & $63 \%$ & $38 \%$ & $100 \%$ \\
\hline \multirow[t]{2}{*}{ NF } & $55 \%$ & $95 \%$ & $9 \%$ & $91 \%$ & $100 \%$ \\
\hline & $100 \%$ & $100 \%$ & & & \\
\hline \multicolumn{6}{|c|}{ Nä̈ve Seasonal Model for comparison } \\
\hline $\mathrm{F}$ & $20 \%$ & $11 \%$ & $5 \%$ & $95 \%$ & $100 \%$ \\
\hline \multirow[t]{2}{*}{ NF } & $80 \%$ & $89 \%$ & $2 \%$ & $98 \%$ & $100 \%$ \\
\hline & $100 \%$ & $100 \%$ & & & \\
\hline
\end{tabular}

Based on $n=365$ days, 40 of which are "fire days".

Refer to Table 3 for key. 
a
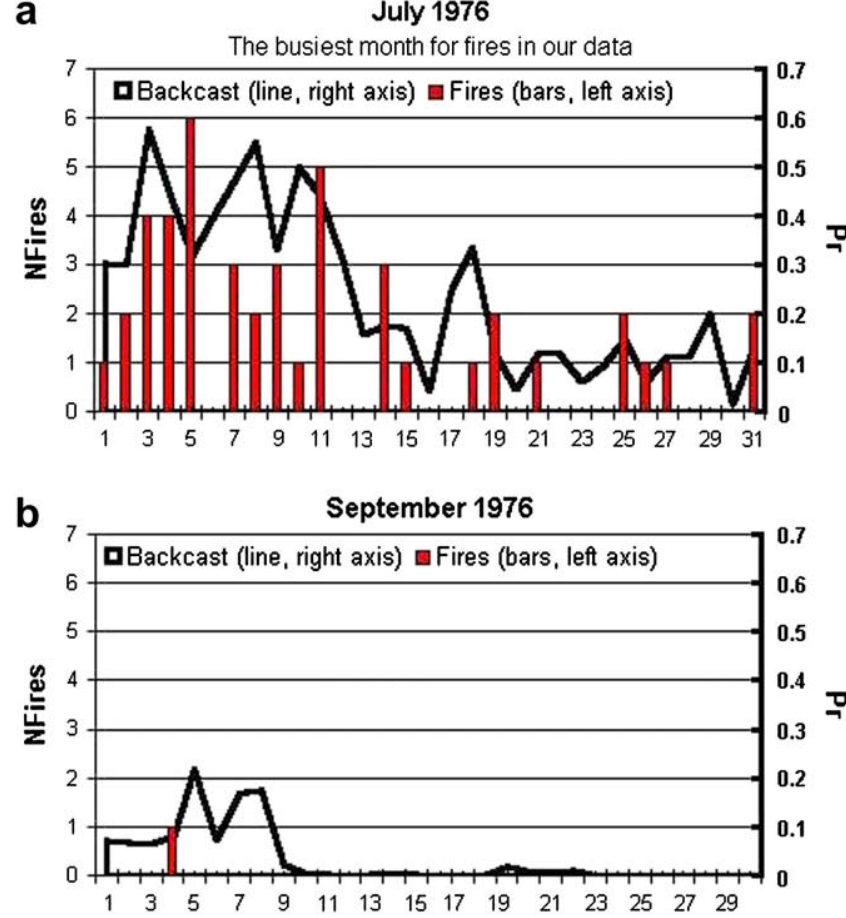

Fig. 5. Backcasts of the probability of a fire compared with actual number of fires.

probit could predict the number of fires, assuming occurrence of fires on any given day is independent. We assume an arsonist on the Peak would not light more than one fire on each day.

In the absence of information on fire severity, the area of a fire can be a proxy for the damage caused. The potential size of fires could be forecast using Tobit analysis (Tobin, 1958; Johnston and DiNardo, 1997, 13), taking account of additional factors such as wind strength and direction. Predictions of fire severity would help deployment of fire fighting resources such as back-up fire tenders, static reservoirs or hydrants. There are statistical difficulties associated with censored regression models of this sort (e.g. Maddala, 1983). Modelling size of fires is also subject to sample selection bias. Small fires are likely to be omitted from the data. The area of very large fires may be under-recorded as it is difficult to estimate coverage of a blaze. There is considerable variation in the precision of estimated areas and fire records do not always include estimates of the size and location of fires. The tapered Pareto distribution is preferred for modelling wildfire size in California (Schoenberg et al., 2003), so assumptions of normality underlying the Tobit model may not be valid with regard to fire area, as opposed to frequency.

Moisture in both vegetation and soil influences flammability. An explanatory variable such as the Keech-Byram drought index for soil moisture deficit might prove a predictor of fire risk. The index is designed to capture the net effect of evapotranspiration and precipitation at the surface and in upper soil layers. However, the UK Meteorological Office (Met Office, 2005; Kitchen et al., 2006) dismiss models based on soil moisture deficit, emphasising fires occur in the spring when ground is wet. Ground moisture levels might be multicollinear with other explanatory variables, notably daily maximum temperature or past rainfall.

\section{Conclusions and qualifications}

A probit model is used to forecast the likelihood of wildfires in the English Peak District National Park at different times of the year, days of the week and under various weather conditions. Current and past rainfall damps fire risk. The chance of fire appears to increase with maximum temperature. Dry spells or recent fire activity may also signal extra fire hazard. Certain days of the week seem more fire prone due to human activity and some months of the year are more risky reflecting the changing flammability of moorland vegetation. The model backcasts the wildfire events of the summer of 1976 successfully.

Climate change is likely to bring wetter winters, but hotter and drier summers to the UK. The probit model suggests incidence of wildfires in the Peak District is likely to be episodic, coinciding with dry spells and hot intervals, especially in summer. Increased winter rainfall may damp down the risk of fires in spring. The impact of climate change may be alleviated if earlier onset of spring adds to plant moisture content. So the incidence of severe fires could shift from spring towards summer.

These results point to a variety of management solutions to reduce the outbreak of fires, to fight fires more effectively and to restore land damaged by wildfire outbreaks. Education of footpath users is a priority. Managed fires might reduce fuel loads and the hazard of wildfire (Davies et al., 2008). The probability model demonstrates global warming may have a damaging effect on a sensitive landscape if adaptation strategies are not pursued.

Simulations suggest changes in climate variability and weather extremes matter more than slight changes in average temperatures or rainfall. The non-linear relationship between the risk of wildfires and key weather variables such as temperature implies that a slight increase in the frequency of isolated periods of hot dry weather might have disastrous impact. Conversely a gentle rise in mean temperature over a long time period may have negligible effect on fire risk, especially if spring starts earlier.

\section{Acknowledgements}

The paper is part of a project on "Climate Change and the Visitor Economy in England's Northwest" funded by the Department for Environment Food and Rural Affairs, the Environment Agency and the Northwest Regional Development Agency, advised by the UK Climate Impacts Programme and led by Professor John Handley of the Centre for Urban and Regional Ecology at the University of Manchester. Moors for the Future compiled the fire database from records kept by Peak District National Park rangers, known as the Fire Rangers' Log. Advice from a Moorland Fires Workshop, from John Logsdon, Justin L. Dean, of the Bureau of Land Management, New Mexico and from Colin Legg and Matt Davies of the Edinburgh Firebeaters group is warmly acknowledged. Three very conscientious and highly perceptive referees helped substantially improve earlier versions of the paper.

This paper was presented to the International Symposium on Forecasting at San Antonio, Texas; a Moors for the Future Workshop, Castleton; and Manchester Statistical Society. Comments by participants are much appreciated.

\section{Appendix 1. Data}

The sample of fires is drawn from record books on the incidence of fires maintained by rangers for the Peak District National Park Authority. The data omits most local grass fires on the urban periphery outside the Park boundary. The majority are moorland fires, falling within the statutory boundary of "section 3 moorland" (Fig. 1). Daily data on the occurrence, number and size of fires runs from June 1976 to July 2004. The period February 1978 to July 2004 was used for estimation. We retain the data for 1976 and 1977 for out-of-sample forecasting to validate the model. 
Weather data is for Buxton (NGR SK 058734; latitude 53.257, longitude -1.913), from the UK Meteorological Office Land Surface Observation Stations database, kindly provided through the British Atmospheric Data Centre (http://badc.nerc.ac.uk) (A full series of data is not available for the preferred moorland weather station, Holme Moss.)

School holiday dates are for a primary school in the City of Salford, one of many in the visitor catchment area. Data was analysed using SPSS version 11.0 and Stata release 8.2

\section{Appendix 2. Explanatory variables}

\begin{tabular}{|c|c|}
\hline Fire past week & $\begin{array}{l}\text { a dummy variable which takes the value " } 1 \text { " if there has } \\
\text { been a fire in the previous seven days }\end{array}$ \\
\hline Multifire & $\begin{array}{l}\text { a dummy variable which takes the value " } 1 \text { " if there has } \\
\text { been a multi-fire day in the previous seven days }\end{array}$ \\
\hline Precipitation & daily precipitation $(\mathrm{mm})$ \\
\hline Minimum temp & daily minimum temperature $\left({ }^{\circ} \mathrm{C}\right)$ \\
\hline Maximum temp & daily maximum temperature $\left({ }^{\circ} \mathrm{C}\right)$ \\
\hline emp range & maximum temp minus minimum temp \\
\hline Bank holiday & $\begin{array}{l}\text { dummy variable which takes the value " } 1 \text { " on a bank } \\
\text { holiday }\end{array}$ \\
\hline School holiday & $\begin{array}{l}\text { dummy variable which takes the value " } 1 \text { " on a school } \\
\text { holiday }\end{array}$ \\
\hline Monday - Sunday & $\begin{array}{l}\text { day of week dummy variables, excluding Wednesday base } \\
\text { day }\end{array}$ \\
\hline February - September & month dummy variables, excluding October base month \\
\hline R7 & $\begin{array}{l}\text { The difference between the (total of the) last seven days' } \\
\text { precipitation (including this day) and the (total) level } \\
\text { expected for that week (the average for this week across } \\
\text { the data set). }\end{array}$ \\
\hline \multicolumn{2}{|c|}{ R14, R21, R28, R56 are similarly defined. } \\
\hline T14 T21 Tרe T5 & $\begin{array}{l}\text { The difference between the (average of the) last seven } \\
\text { days' temperature (including this day) and the (average) } \\
\text { level expected for that week (the average for this week } \\
\text { across the data set). }\end{array}$ \\
\hline \multicolumn{2}{|c|}{ T14, T21, T28 and T56 are similarly defined. } \\
\hline IR7 & $\begin{array}{l}\text { An event dummy which switches "on" (takes the value } \\
\text { "1") if weekly average precipitation is } 1.28 \text { standard } \\
\text { deviations below average for the time of year (the bottom } \\
\text { decile). Once activated, the indicator remains "on" until } \\
\text { a week's rainfall is above the average. }\end{array}$ \\
\hline IT7 & $\begin{array}{l}\text { An event dummy which switches "on" (takes the value } \\
\text { "1") if weekly average maximum temperature is } 1.28 \\
\text { standard deviations above average for the time of year } \\
\text { (the top decile). Once activated, the indicator remains } \\
\text { "on" until a week's maximum temperature is above the } \\
\text { average. }\end{array}$ \\
\hline
\end{tabular}

Note weather data was obtained for dates prior to the sample period to calculate the relevant rainfall and temperature shadows.

\section{References}

Abramson, B., Brown, J., Edwards, W., Murphy, A., Winkler, R.L., 1996. Hailfinder: a Bayesian system for forecasting severe weather. Int. J. Forecasting 12 (1), 57-71.

Agnew, M.D., 1997. Tourism. In: Palutikof, J.P., Subak, S., Agnew, M.D. (Eds.) Economic Impacts of the Hot Summer and Unusually Warm Year of 1995. Department of the Environment, London, pp. 157-162.

Albertson, K., Aylen, J., 1996. Modelling the Great Lakes Freeze: forecasting and seasonality in the market for ferrous scrap. Int. J. Forecasting 12 (3), 345-359.

Anderson, P., 1986. Accidental Moorland Fires in the Peak District: a Study of their Incidence and Ecological Implications. Peak District Moorland Restoration Project, Buxton.

Anderson, P.A., Tallis, J.H., Yalden, D.W., 1997. Restoring Moorlands: the Moorland Management Project Phase 3 Report. Peak Park Joint Planning Board, Bakewell.

Aylen, J., Albertson, K., Cavan, G., 2006. Visitor attraction figures in relation to climate: the potential impact of global climate change on zoos. In: Proceedings of the 5th International Conference on Zoo Marketing and Public Relations. Allwetterzoo Münster, Germany. WAZA, Bern, Switzerland, pp. 79-87.

Burington, R.S., 1973. Handbook of Mathematical Tables and Formulas, fifth ed. McGrawHill, New York.

Chandler, R.E., Wheater, H.S., 1998. Climate Change Detection using Generalized Linear Models for Rainfall - a Case Study from the West of Ireland, II. Modelling of Rainfall Amounts on Wet Days. Research Report no. 195.. University College London, Department of Statistical Science, London. Available from: http://www. ucl.ac.uk/Stats/research/Resrprts/abs98.html (accessed 20.06.05).

Coe, R., Stern, R.D., 1982. Fitting models to daily rainfall data. J. Appl. Meteorol 21 1024-1031.

Davidson, J.E.H., Hendry, D.F., Srba, F., Yeo, S., 1978. Econometric modelling of the aggregate time-series relationship between consumers' expenditure and income in the United Kingdom. Econ. J. 88 (352), 661-692.

Davies, G.M., 2005. Fire Behaviour and Impact on Heather Moorland. PhD. The University of Edinburgh.

Davies, G.M., Gray, A., Hamilton, A., Legg, C.J., 2008. The future of fire management in the British uplands. Int. J. Biodivers. Sci. Manag. 4 (3), 127-147.

Davison, A.C., Smith, R.L., 1990. Models for exceedances over high thresholds. J. Roy. Stat. Soc., B Met. 52 (3), 393-442.

Dayananda, P.W.A., 1977. Stochastic models for forest fires. Ecol. Model 3 (4), 309-313.

DEFRA, Department for Environment, Food and Rural Affairs (formerly Ministry of Agriculture, Fisheries and Food), 1992. The Heather and Grass Burning Code. MAFF Publications, London, PB 1029 formerly at http://www.defra.gov.uk/rds/ hgbc.pdf accessed 9th June 2005 now in revised form at: http://www. naturalengland.org.uk/planning/farming-wildlife/burning/docs/ HeatherGrassBurningCode.pdf (accessed 28.11.08).

Franses, P.H., 1996. Periodicity and Stochastic Trends in Economic Time-series. Oxford University Press.

Gaines, S.D., Denny, M.W., 1993. The largest, smallest, highest, lowest, longest, and shortest: extremes in ecology. Ecology 74 (6), 1677-1692.

Gilbert, C.L., 1986. Professor Hendry's econometric methodology. Oxford B. Econ. Stat. 48 (3), 283-307.

Giles, A.R., Perry, A.H., 1998. The use of a temporal analogue to investigate the possible impact of projected global warming on the UK tourist industry. Tourism Manag. 19 (1), 75-80.

Gray, A., 2006. The Influence of Management on the Vegetation and Carbon Fluxes of Blanket Bog. PhD. The University of Edinburgh.

Hylleberg, S., Engle, R.F., Granger, C.W.J., Yoo, B.S., 1990. Seasonal integration and cointegration. J. Econometrics 44 (1-2), 215-238.

Hulme, M., Jenkins, G.J., Lu, X., Turnpenny, J.R., Mitchell, T.D., Jones, R.G., Lowe, J., Murphy, J.M., Hassell, D., Boorman, P., McDonald, R., Hill, S., 2002. Climate Change Scenarios for the United Kingdom. the UKCIP02 scientific report. United Kingdom Climate Impacts Programme, Oxford.

Johnston, J., DiNardo, J., 1997. Econometric Methods, fourth ed. McGrawHill, New York.

Kallache, M., Rust, H.W., Kropp, J., 2005. Trend assessment: applications for hydrology and climate research. Nonlinear Process. Geophys. 12 (2), 201-210.

Katz, R.W., Brush, G.S., Parlange, M.B., 2005. Statistics of extremes: modelling ecological disturbances. Ecology 86 (5), 1124-1134.

Kitchen, K., Marno, P., Legg, C., Bruce, M., Davies, M., 2006. Developing a fire danger rating system for the United Kingdom (Abstract). Forest Ecol. Manag. 234 (Suppl. S21), 15.

Mackay, A.W., Tallis, J.H., 1996. Summit-type blanket mire erosion in the forest of Bowland, Lancashire, UK: predisposing factors and implications for conservation. Biol. Conserv. 76 (1), 31-44.

Maddala, G.S., 1983. Limited-Dependent and Qualitative Variables in Econometrics. Cambridge U.P.

Maltby, E., Legg, C.J., Proctor, M.C.F., 1990. The ecology of severe moorland fire on the North York Moors: effects of the 1976 fires, and subsequent surface and vegetation development. J. Ecol. 78 (2), 490-518.

Mandallaz, D., Ye, R., 1997. Prediction of forest fires with Poisson models. Can. J. For Res. 27 (10), 1685-1694.

Maraun, D., Osborn, T.J., Gillett, N.P., 2008. United Kingdom daily precipitation intensity: improved early data, error estimates and an update from 2000 to 2006. Int. J. Climatol. 28 (6), 833-842.

Martell, D.L., Otukol, S., Stocks, B.J., 1987. A logistic model for predicting daily people-caused forest fire occurrence in Ontario. Can. J. For. Res. 17 (5), 394-401.

Mayes, J., 1996. Spatial and temporal fluctuations of monthly rainfall in the British Isles and variations in the mid-latitude westerly circulation. Int. J. Climatol. 16 (5), 585-596.

McEvoy, D., Handley, J.F., Cavan, G., Aylen, J., Lindley, S., McMorrow, J., Glynn, S. 2006. Climate Change and the Visitor Economy: Challenges and Opportunities for England's Northwest. UKCIP and Sustainability Northwest, Oxford and Manchester.

McMorrow, J, Aylen, J., Albertson, K, Cavan, G, Lindley, S, Handley, J., Karooni, R. 2006. Moorland Wildfires in the Peak District National Park, Peak District Case Study, Technical Report 3. Centre for Urban and Regional Ecology, Manchester University, Manchester. Available from: http://www.snw.org.uk/tourism/ downloads/Moorland_Wildfires_Final_Report.pdf (accessed 28.08.08).

McMorrow, J.M., Lindley, S.J., Aylen, J., Cavan, G., Albertson, K., Boys, D., 2009 Moorland wildfire risk, visitors and climate change: patterns, prevention and policy. In: Bonn, A., Hubacek, K., Allott, T., Stewart, J. (Eds.), Drivers of Environmental Change in Uplands. Routledge, Abingdon ch. 23.

Met Office, 2005. The Met Office Fire Severity Index for England and Wales Prepared for: Countryside Agency, Countryside Council for Wales and the Forestry Commission MetO ref: M/BO/P87. Exeter, Met Office, Available from: http://www.openaccess.gov.uk/wps/portal/!ut/p/.cmd/cs/.ce/7_0_A/.s/7_0_ G3/_s.7_0_A/7_0_G3 (accessed 28.08.08). 
Milne, R., Brown, T.A., 1997. Carbon in the vegetation and soils of Great Britain. J. Environ. Manag. 49 (4), 413-433.

Morehouse, B.J., 2001. Climate, forest fires, and recreation: insights from the U.S Southwest. In: Matzarakis, A., de Freitas, C.R. (Eds.), Proceedings of the First International Workshop on Climate, Tourism and Recreation. International Society of Biometeorology, Porto Carras, Halkidiki, Greece, pp. 41-50. Available from: http://www.mif.uni-freiburg.de/isb/ws/report.htm (accessed 25.05.05).

Osborn, T.J., Hulme, H., Jones, P.D., Basnett, T.A., 2000. Observed trends in the daily intensity of United Kingdom precipitation. Int. J. Climatol. 20 (4), 347-364.

Osborn, T.J., Hulme, H., 2002. Evidence for trends in heavy rainfall events over the UK. Philos. T. Roy. Soc. A 360 (1796), 1313-1325.

Palutikof, J.P., 1997. Fire. In: Palutikof, J.P., Subak, S., Agnew, M.D. (Eds.), Economic Impacts of the Hot Summer and Unusually Warm Year of 1995. Department of the Environment, London, pp. 157-162.

Preisler, H.K., Brillinger, D.R., Burgan, R.E., Benoit, J.W., 2004. Probability based models for estimation of wildfire risk. Int. J. Wildland Fire 13 (2), 133-142.

Radley, J., March 27, 1965. Significance of major moorland fires. Nature 215, 1254-1259.

Rothwell, J.J., Robinson, S.G., Evans, M.G., Yang, J., Allott, T.E.H., 2005. Heavy metal release by peat erosion in the Peak District, southern Pennines, UK. Hydrol. Process. 19 (15), 2973-2989.

Schoenberg, F.P., Peng, R., Woods, J., 2003. On the distribution of wildfire sizes. Environmetrics 14 (6), 583-592.

Scott Armstrong, J., 2001. Evaluating forecasting methods. In: Scott Armstrong, J. (Ed.), Principles of Forecasting: A Handbook for Researchers and Practitioners. Kluwer, Boston, pp. 443-472.

Shackley, S., Wood, R., Hornung, M., Hulme, M., Handley, J., Darier, R., Walsh, M. 1998. Everybody Has An Impact: Changing By Degrees: the Impact of Climate Change in the North West of England. Sustainability Northwest, Manchester.

Shaw, S.C., Wheeler, B.D., Kirby, P., Phillipson, P., Edmunds, R., 1996. Literature Review of the Historical Effects of Burning and Grazing of Blanket Bog and Upland Wet Heath. English Nature Research Reports, Number 172. English Nature and Countryside Council for England and Wales, Peterborough.

Spanos, A., 1999. Probability Theory and Statistical Inference: Econometric Modelling with Observational Data. Cambridge U.P.
Sparks, T.H., Jeffree, E.P., Jeffree, C.E., 2000. An examination of the relationship between flowering times and temperature at the national scale using long-term phenological records from the UK. Int. J. Biometeorol. 44 (2), 82-87.

Stern, R.D., Coe, R., 1984. A model fitting analysis of rainfall data. J. Roy. Stat. Soc., A-G 147 (1), 1-34.

Tallis, J.H., 1981. Uncontrolled fires. In: Phillips, J., Yalden, D., Tallis, J. (Eds.), Moorland Erosion Study, Phase 1 Report. Peak Park Joint Planning Board, Bakewell, pp. 176-182.

Tallis, J.H., 1987. Fire and flood at Holme Moss: erosion processes in an upland blanket mire. J. Ecol. 75 (4), 1099-1129.

Thompson, R., 1999. A time-series analysis of the changing seasonality of precipitation in the British Isles and neighbouring areas. J. Hydrol. 224, 169-183.

Tobin, J., 1958. Estimation of relationships for limited dependent variables. Econometrica 26 (1), 24-36.

Vega Garcia, C., Woodard, P.M., Titus, S.J., Adamowicz, W.L., Lee, B.S., 1995. A logit model for predicting the daily occurrence of human caused forest fires. Int. J. Wildland Fire 5 (2), 101-111.

Ward, S.E., Bardgett, R.D., McNamara, N.P., Adamson, J.K., Ostle, N.J., 2007. Longterm consequences of grazing and burning on northern peatland carbon dynamics. Ecosystems 10 (7), 1069-1108.

Watt, A.S., 1954. Contributions to the ecology of bracken (Pteridium Aquilinum), VI. Frost and the advance and retreat of bracken. New Phytol. 53 (1), 117-130.

Woodward, W., Gray, H., 1995. Selecting a model for detecting the presence of a trend. J. Clim. 8 (8), 1929-1937.

Wotton, B.M., Flannigan, M.D., 1993. Length of the fire season in a changing climate. For. Chron. 69 (2), 187-192.

Wotton, B.M., Martell, D.L., Logan, K.A., 2003. Climate change and people-caused forest fire occurrence in Ontario. Clim. Change 60 (3), 275-295.

Yallop, A.R., Thacker, J.I., Thomas, G., Stephens, M., Clutterbuck, B., Brewer, T., Sannier, C.A.D., 2006. The extent and intensity of management burning in the English uplands. J. Appl. Ecol. 43 (6), 1138-1148.

Yeloff, D.E., Labadz, J.C., Hunt, C.O., 2005. The suitability of a South Pennine (UK) reservoir as an archive of recent environmental change. J. Paleolimnol. 34 (3), 339-348. 